\title{
PARTIAL SPLENECTOMY FOR HYDATID CYST IN PAEDIATRIC PATIENT
}

Jaykar R. D ${ }^{1}$, Kasabe P. S², Korde Paresh ${ }^{3}$

\section{HOW TO CITE THIS ARTICLE:}

Jaykar R. D, Kasabe P. S, Korde Paresh. "Partial Splenectomy for Hydatid CYST in Paediatric Patient". Journal of Evolution of Medical and Dental Sciences 2014; Vol. 3, Issue 22, June 02; Page: 6225-6228,

DOI: $10.14260 /$ jemds/2014/2726

ABSTRACT: Pediatric patient, operated case of enucleation of hydatid cyst of lung associated with splenic hydatid disease treated with partial splenectomy with preservation of splenic function is reported and the literature reviewed briefly.

KEYWORDS: Hydatid cyst, partial splenectomy.

INTRODUCTION: The classification of cyst of spleen in to primary (Type-I), which may be parasitic or nonparasitic and secondary (Type-II) was proposed by Martin. ${ }^{1}$ The commonest cause of parasitic cyst is Taenia Ecchinococcus. ${ }^{2}$ Splenic involvement is rare in patients with hydatid disease even in endemic countries.

The incidence of splenic hydatids reported by different workers from different cities of India are 3.3\% Indore, 2\% Ahmedabad, 4.2\% Irwin hospital Delhi, 2.7\% Pondicherry and 6.3\% Nagpur. The spleen is third most common organ in hydatid after liver and lung considering involvement. Splenectomy is the conventional treatment, but there are other treatment options also available like marsupialization, omentopexy.

Most recent reports describe successful experience with partial splenectomy, cyst wall resection or partial decapsulation, which may be accomplished with either an open or laparoscopic approach.3,4,5 Partial splenectomy is the emerging treatment option for hydatid disease. The clear advantage of partial splenectomy is preservation of splenic function. Preservation of at least $25 \%$ of spleen appears sufficient to protect against pneumococcal pneumonia.

CASE HISTORY: A 9 years old male patient admitted with chief complaints of fever, breathlessness, right side chest pain since 10 days. H/O gradually increasing swelling in left hypochondriac region associated with dull dragging pain since 1 month. $\mathrm{H} / \mathrm{O}$ of weakness and weight loss since 45 days.

On examination patient was averagely built with decreased air entry in right lower axillary region. Abdominal examination revealed smooth, nontender, firm cystic mass in spleen in the left hypochondria, moving well with respiration.

Hemoglobin was $11 \mathrm{gm} / \mathrm{dl}$. Differential count showed polymorphonuclear leukocytosis. Chest X-ray showed right sided consolidation.

Abdominal sonography was suggestive of $8.9 \mathrm{~cm}$ x $8.5 \mathrm{~cm} \times 7 \mathrm{~cm}$ splenic hydatid cyst.

CT thorax suggestive of $5.5 \times 5 \mathrm{~cm}$, well defined hydatid cyst in right lower Lobe of lung and $8.6 \times 8 \times 7 \mathrm{~cm}$ splenic hydatid cyst.

MANAGEMENT: Patient was operated for enucleation of lung cyst earlier. 6 month later, patient underwent partial splenectomy. 


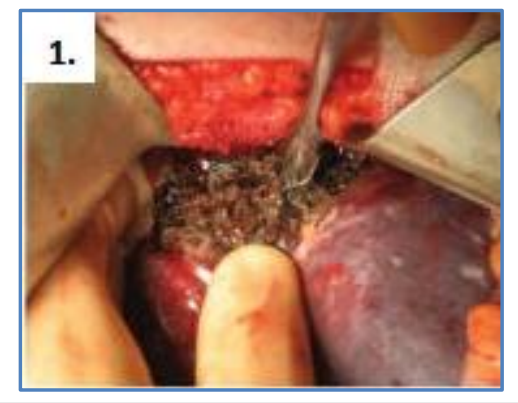

Fig. 1: Raw surface of spleen after partial splenectomy

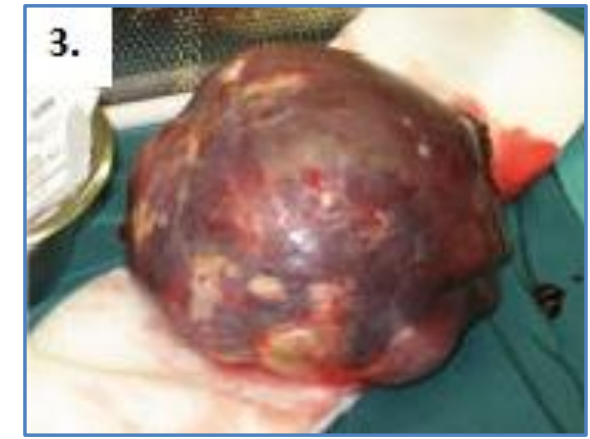

Fig. 3: Resected specimen of lower pole of spleen with hydatid cyst

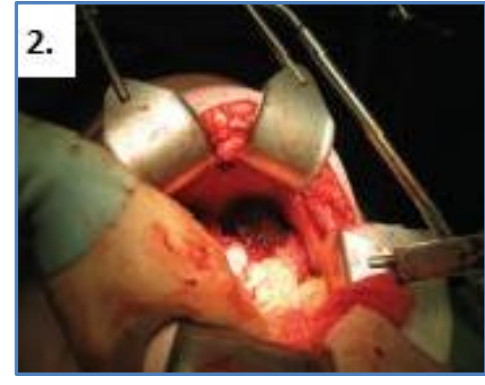

Fig. 2: Intraoperative picture

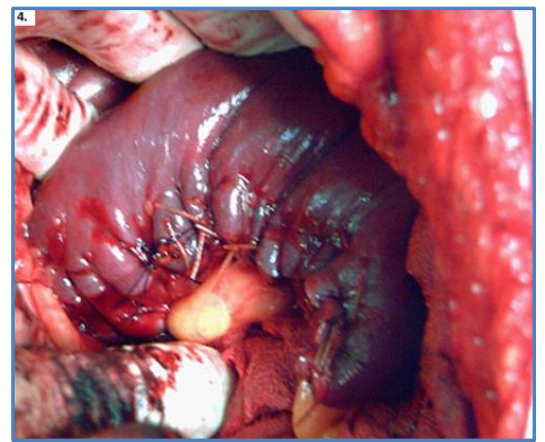

Fig. 4: Sutured spleen after partial splenectomy

DISCUSSION: Hydatid cyst is the only parasitic cyst o the spleen and is said to be twice as common as the nonparasitic variety. The relative infrequency of hydatid cysts of the spleen is because liver filter stops $75 \%$ and lug filter stops $15 \%$ of the embryo so that only $10-15 \%$ are left to develop into cysts in other parts of the body. Hydatid cysts have been reported in almost every organ of the body, mostly in liver, lungs and spleen.

The rarer sites include skull, thyroid, hip joint, spinal cord, central nervous system, kidneys, breast, leg etc. In India incidence of hydatid cysts at unusual sites is higher as compared to other parts of the world. Hydatids at these unusual sites present difficulties in clinical diagnosis. Ribero in a 10 year study from Jammu did not report a single case of hydatid spleen out of 87 cases of hydatid diseases.

The route of splenic invasion is controversial and the various theories put forth include:

- Spread through blood stream and lymphatics,

- Reflux into spleen from the portal vein, from haemorrhoidal veins after short circuiting the liver and lung filters, through small veins passing from the splenic flexure of the colon to the lower pole of the spleen, via arterial blood,

- Direct migration from liver and middle haemorrhoidal veins without passing through the liver,

- Migration through chyliferous ducts and thoracic ducts into superior vena cava and general circulation after penetration of intestinal wall and direct entry into spleen from stomach and colon across the actual or potential spaces or via lymphatics. 
Despite these theories, the most probable route involves escaping of 10 to 255 of embryos from liver and lung filters into general circulation, a fraction of which settles down in the spleen. The cyst may lodge in the interior of the spleen or at its periphery. It may lie beneath the capsule or outside it or it may remain attached to the spleen by a pedicle, which may be broad or narrow.

Hydatid cyst of the spleen may be symptomless or produce symptoms mainly because of mechanical presence. The symptoms usually include painless swelling o abdomen, pain which is usually dull dragging ache, constipation due to pressure on the colon and dyspnea due to pushing up of the diaphragm. The cyst may get infected or rupture into a hollow viscus or the general peritoneal cavity.

The cyst may become adherent to the skin and discharge daughter cysts to the surface. Hydatid fremitus may be demonstrated. Plain X-ray may show soft tissue shadow or calcified ball like picture. Blood shows mainly eosinophilia. Abdominal ultrasonic examination and several immunological tests confirm the diagnosis. Mostly patient will present with pain in abdomen or mass in let upper abdomen or both. Differential count shows mostly polymorphonuclear leukocytosis.

The treatment of splenic hydatid cyst is surgical and the procedure mainly used is splenectomy. Marsupialization, introduction of the greater omentum into the cavity of the cyst after enucleation and evacuation with closure of the cyst and fixation to the wall have gone into disrepute. By partial splenectomy, splenic function can be conserved. Hence it can prevent the infection from S. pneumonia, which is most frequently involved organism in splenectomy patients. ${ }^{6}$ Moreover splenic absence provides a relative dead space in left upper quadrant, which often becomes occupied with blood clot or serum, creating a potential space for subphrenic abscess. Hence partial splenectomy is found to be more beneficial, especially in paediatric age group.

Nonparasitic cysts have been treated with splenic conserving surgery. ${ }^{7}$

In study be Atmatzidis K, it was possible to preserve the spleen in 8 out of 19 patients, without significant increase of recurrent echinococcusis. ${ }^{8}$ Although currently splenectomy is the conventional treatment, experience suggest that partial splenectomy and omentopexy should be the procedure of choice for the treatment of splenic hydatidosis. ${ }^{9,10}$ In the laparoscopic era, laparoscopic splenectomy or various benign conditions was found to be feasible and superior to open splenectomy.

This was followed by laparoscopic partial splenectomy for nonparasitic cysts.

Laparoscopic partial splenectomy can be done successfully, provided that the cyst is prominent on the surface or at one pole and adequate precaution are taken to avoid injury or minimal leak. ${ }^{11,12}$

\section{REFERENCES:}

1. Martin J W. Congenital splenic cysts. Am J Surg. 96: 302, 1958.

2. Fowler RH. Further studies of cysts of the spleen. Ann Surg. 80: 59-61, 1924.

3. Sardi A, Ojeda HF, King D jr. Laparoscopic resection of benign true cyst of spleen with harmonic scalpel producing high levels of CA 19-9 and CEA. Am J Surg, 64: 1149-1154, 1998.

4. Tsakayannis DE, Mitchell $\mathrm{K}$ et al. Splenic preservation in management of splenic epidermoid cyst in children. J Pediatr Surg 30: 1468-1470, 1995.

5. Touloukian RJ, Maharaj A et al. Partial decapsulation of splenic epithelial cysts: Study on etiology and outcome. J Paed Surg. 32: 272-274, 1997. 


\section{CASE REPORT}

6. Gold Thron JF, Schwartz AD et al. Protective effect residual splenic tissue after subtotal Splenectomy. J Paed Surg. 13: 587-590, 1978.

7. Miller JS Partial excision and drainage of posttraumatic splenic cyst. Br J Surg. 69: 477-478, 1982.

8. Atmatzidis K, Papaziogas B, Mirelis C, Pavlidis T, Papaziogas T. Splenectomy versus spleen preserving surgery for splenic echinococcosis. Dig Surg. 2003: 20(6): 527-31. Epub 2003 Sep.

9. Ozdogan M, Baykal A, Keskek M, Yorgancy K, Hamaloglu E, Sayek I. Hydatid cyst of the spleen: treatment options. Int surg. 2001 Apr-Jun: 86(2): 122-6.

10. Lopez Gibert J, Sedo Fortuny R, Ramirez Felipe JA. Partial splenectomy in hydatid cyst of the spleen. Rev Esp Enferm Apar Dig. 1982 Sep; 62(3): 224-7. Spanish 24.

11. Dar MA, Shah OJ, Wani NA, Khan FA, Shah P. Surgical management of splenic hydatidosis. Surg Today. 2002; 32(3): 224-9.

12. Gharaibeh KI. Laparoscopic excision of splenic hydatid cyst. Postgrad Med J. 2001 Mar; 77(905): 195-6.

\section{AUTHORS:}

1. Jaykar R. D.

2. Kasabe P.S.

3. Korde Paresh

\section{PARTICULARS OF CONTRIBUTORS:}

1. Associate Professor, Department of Surgery, Dr. V. M. Government Medical College, Solapur.

2. Assistant Professor, Department of Surgery, Dr. V. M. Government Medical College, Solapur.

3. Resident, Department of Surgery, Dr. V. M. Government Medical College, Solapur.

\section{NAME ADDRESS EMAIL ID OF THE CORRESPONDING AUTHOR: \\ Dr. Paresh Korde, Department of General Surgery, $3^{\text {rd }}$ Floor, B Block, Civil Hospital, Solapur-413003. \\ Email:pkthehunk@gmail.com}

Date of Submission: 02/05/2014. Date of Peer Review: 03/05/2014. Date of Acceptance: 20/05/2014. Date of Publishing: 02/06/2014. 